\title{
Psychiatric Co-occurring Symptoms and Disorders in Young, Middle-Aged, and Older Adults with Autism Spectrum Disorder
}

\author{
Anne G. Lever ${ }^{1} \cdot$ Hilde M. Geurts ${ }^{1,2}$
}

Published online: 9 February 2016

(c) The Author(s) 2016. This article is published with open access at Springerlink.com

\begin{abstract}
Although psychiatric problems are less prevalent in old age within the general population, it is largely unknown whether this extends to individuals with autism spectrum disorders (ASD). We examined psychiatric symptoms and disorders in young, middle-aged, and older adults with and without ASD $\left(\mathrm{N}_{\max }=344\right.$, age 19-79 years, IQ > 80). Albeit comparable to other psychiatric patients, levels of symptoms and psychological distress were high over the adult lifespan; $79 \%$ met criteria for a psychiatric disorder at least once in their lives. Depression and anxiety were most common. However, older adults less often met criteria for any psychiatric diagnosis and, specifically, social phobia than younger adults. Hence, despite marked psychological distress, psychiatric problems are also less prevalent in older aged individuals with ASD.
\end{abstract}

Keywords Autism spectrum disorder · Psychiatric comorbidity $\cdot$ Aging $\cdot$ Adults $\cdot$ Depression $\cdot$ Anxiety

Electronic supplementary material The online version of this article (doi:10.1007/s10803-016-2722-8) contains supplementary material, which is available to authorized users.

Anne G. Lever

A.G.Lever@uva.nl

1 Dutch Autism and ADHD Research Center, Department of Psychology, University of Amsterdam, Nieuwe Achtergracht 129B, 1018 WT Amsterdam, The Netherlands

2 Dr. Leo Kannerhuis, Research Development and Innovation, Houtsniplaan 1a, 6865 XZ Doorwerth, The Netherlands

\section{Introduction}

Psychopathology is a frequently occurring phenomenon. In the general population, approximately $40 \%$ meets criteria for a psychiatric disorder at least once in their lives (Bijl et al. 1998; Kessler et al. 2005). This rate is much higher in individuals with an autism spectrum disorder (ASD), a heterogeneous neurodevelopmental disorder characterized by atypicalities in social communication and interaction and repetitive stereotyped behavior (American Psychiatric Association 2013). In this population, at least $69 \%$ is thought to suffer from co-occurring psychiatric disorders and symptoms (Buck et al. 2014), even though rates are lower in individuals with ASD and intellectual disability (ID) (Howlin and Moss 2012; Matson and Cervantes 2014). The presence of co-occurring disorders is associated with lower quality of life, greater demands for professional help, poorer prognosis, greater interference with everyday life, and worse outcome (Lainhart 1999; Matson and Cervantes 2014; Seltzer et al. 2004; Vannucchi et al. 2014; Wood and Gadow 2010). Furthermore, specifically the cooccurring symptoms and disorders often constitute a target for treatment, leading to an amelioration of problems. For example, various psychotropic medications are frequently prescribed to individuals with ASD to treat associated symptoms (Aman et al. 2005; Buck et al. 2014; Esbensen et al. 2009; Logan et al. 2015; Seltzer et al. 2004). As ASD is considered a lifelong disorder (Piven et al. 1996; Seltzer et al. 2004) and symptoms of psychopathology are likely to wax and wane across the adult lifespan, knowledge regarding associated psychopathology in older adulthood is needed (Matson and Cervantes 2014; Perkins and Berkman 2012) to be able to provide adequate support for these older individuals. This will be the focus of the current study. 
In the general population, age is a relevant factor for psychopathology. The prevalence of psychiatric disorders and their nature is different in older adulthood than in middle or young adulthood (Bijl et al. 1998; Kessler et al. 2005). While the general prevalence of psychiatric disorders is lower, the prevalence of, for example, alcohol or substance related disorders decreases sharply with increasing age, whereas depression and anxiety are still highly prevalent (Beekman et al. 1998; Wolitzky-Taylor et al. 2010).

While traditionally many ASD studies mainly focused on co-occurring symptoms and disorders in childhood (de Bruin et al. 2007; Leyfer et al. 2006; Lundström et al. 2015; Mattila et al. 2010; Mukaddes et al. 2010; Simonoff et al. 2008; Sinzig et al. 2009; van Steensel et al. 2013; Verheij et al. 2015), recently a steadily increasing number of studies have taken into account co-occurring symptoms and disorders in adulthood (Buck et al. 2014; Cervantes and Matson 2015; Croen et al. 2015; Ghaziuddin and Zafar 2008; Hofvander et al. 2009; Joshi et al. 2013; Lugnegård et al. 2011; Maddox and White 2015; Roy et al. 2015). These findings seem to suggest that also in the ASD population age is an important factor. In childhood, attention deficit hyperactivity disorder (ADHD), behavioral disorder, and anxiety disorders are the most prevalent comorbid disorders (de Bruin et al. 2007; Leyfer et al. 2006; Simonoff et al. 2008; Sinzig et al. 2009), whereas in adulthood, next to ADHD and anxiety disorders, mood disorders are common (Croen et al. 2015; Ghaziuddin et al. 2002; Ghaziuddin and Zafar 2008; Hofvander et al. 2009; Joshi et al. 2013; Roy et al. 2015; Sterling et al. 2008). In various adult studies, older adults with ASD have been included but only a few directly compared older adults with younger individuals (Roy et al. 2015; Totsika et al. 2010). In an intellectually challenged (ID) sample, psychiatric disorders were less frequent in older adults with ASD and ID compared to younger adults with ASD and ID (Totsika et al. 2010). In contrast, in older adults with ASD without ID, co-occurring psychiatric disorders were more common than in younger adults (Roy et al. 2015). Unfortunately, the "older group" in this latest study was relatively young (age range 40-62 years), the sample was small, and a statistical comparison was lacking. A few studies focused on specific psychiatric disorders such as anxiety (Davis et al. 2011) and depression (Ghaziuddin et al. 2002). Whereas anxiety seemed to reduce from childhood to young adulthood (Davis et al. 2011), the risk for depression seemed to increase with increasing age (Ghaziuddin et al. 2002). A small study in older adults (53-83 years) with ASD reported high levels of psychological and somatic complaints and of psychological distress (van Heijst and Geurts 2014). However, it has not been tested whether these participants encountered a sufficient number of psychiatric symptoms to meet diagnostic criteria, although also associated symptoms in itself may cause clinically relevant distress and impairment that may interfere with quality of life and daily functioning. Thus, the nature and prevalence of comorbid psychopathological symptoms and disorders in older adults with ASD is largely unknown. In the current study, we will, therefore, determine both the occurrence of non-ASD symptomatology and co-occurring psychiatric disorders across the adult lifespan in ASD by comparing young, middle-aged, and older adults clinically diagnosed with ASD without ID. We hypothesize psychiatric co-occurring symptoms and disorders to be substantially higher in individuals with ASD than in controls over the whole adult lifespan, but comparable to a normative group of policlinic psychiatric patients (Joshi et al. 2013). Given the mixed findings so far (Davis et al. 2011; Roy et al. 2015; Totsika et al. 2010), we will examine whether there will be differences in this co-occurrence of other psychiatric symptoms and disorders between the three age groups.

In addition to age, several other factors might affect the prevalence of comorbid psychiatric disorders in individuals with ASD, including ASD severity, gender, social economic status (i.e., education and work), living situation, and both intellectual and more general cognitive functioning. We will explore their role with respect to the cooccurring psychopathology in adults with ASD. For example, in the general population vulnerability factors for developing anxiety or depression are, among others, cognitive decline, being female, having a lower social economic status, or not having a partner (Beekman et al. 1998). In the ASD literature the focus has been mainly on ASD severity, gender, and intellectual functioning but whether these factors are indeed risk factors for comorbid psychopathology in ASD is a topic of debate as results are rather inconsistent (Cederlund et al. 2010; García-Villamisar and Rojahn 2015; Gotham et al. 2015; Holtmann et al. 2007; Jang and Matson 2015; Lai et al. 2011; Lugnegård et al. 2011; Moss et al. 2015; Simonoff et al. 2008, 2013; Sterling et al. 2008; Tureck et al. 2014; van Steensel et al. 2012; Verheij et al. 2015). To restrict the number of analyses we will solely explore whether all these aforementioned factors are indeed risk factors correlated with the most commonly co-occurring disorders in adults with ASD, which we expect to be mood and anxiety disorders (see for a similar approach in children Simonoff et al. 2008, 2013). 


\section{Methods}

\section{Participants}

Two-hundred-forty-seven adults with ASD between 19 and 79 years were recruited through several mental health institutions across the Netherlands and by means of advertisements on client organization websites. Individuals with ASD traits, but without a prior clinical diagnosis of ASD based on DSM-IV criteria (autism, Asperger's syndrome, and Pervasive Developmental Disorder Not Otherwise Specified) (American Psychiatric Association 2000), which was generally diagnosed by a multidisciplinary team involving a psychologist and/or psychiatrist, ${ }^{1}$ were not eligible to participate in the study.

Two-hundred-eight adults without ASD [comparison (COM) group] were recruited by means of advertisements on the university website and on social media, and within the researchers' social environment. Individuals with a considerable amount of autistic traits, as measured with the Autism-spectrum Quotient (AQ > 32) (Baron-Cohen et al. 2001), or with close family members having ASD or schizophrenia, were excluded.

For both groups, additional requirement upon participation was an absent history of neurological disorders (e.g., epilepsy, stroke, cerebral contusion) or schizophrenia. Four-hundred-five individuals met these prerequisites (216 ASD, $189 \mathrm{COM}$ ). The study consisted of two parts. Part I included the administration of a questionnaire on psychological symptoms and distress and medication usage, which was completed by 344 individuals (172 ASD, $172 \mathrm{COM}$ ) who constituted the final sample of Part I. Part II included the administration of a neuropsychiatric interview to examine psychiatric disorders and an analysis of potential risk factors, and was part of a larger study assessing age-related differences in cognition (Lever \& Geurts 2015a). Eligible ASD individuals were selected based on age to ascertain that participants were evenly distributed across ages. IQ was estimated with two subtests of the Dutch Wechsler Adult Intelligence Scale third edition (WAIS-III) (Uterwijk 2000; Wechsler 1997) and the diagnoses of the ASD participants were verified by administering the Autism

\footnotetext{
${ }^{1}$ Please note that the Dutch multidisciplinary guidelines (Trimbos 2013), based on the UK guidelines (National Institute for Health and Clinical Excellence 2012), for diagnosis and treatment of ASD in adults recommends that ASD is diagnosed by a psychiatrist or psychologist experienced in diagnosing ASD who is embedded within a multidisciplinary team, that review of developmental history is necessary (but can be left out when unreliable, despite several attempts to obtain it and when there are well-founded other clinical indications of ASD being concerned), that multiple informants should be asked about current functioning, and that assessment of co-existing conditions should be included.
}

Diagnostic Observation Schedule module 4 (ADOS) (de Bildt and de Jonge 2008; Lord et al. 2000). Four individuals (2 ASD, 2 COM) had an estimated IQ below 80 and were excluded from the sample of Part II. Of the remaining 138 ASD participants, 37 scored below the ADOS cut-off for ASD $(<7), 49$ below the autism threshold $(<10)$, and 52 above the autism threshold $(\geq 10)$. As all these individuals had a clinical diagnosis within the autism spectrum, diagnosed independently from the present study by mental health professionals, and the concordance between clinical diagnosis and ADOS module 4 classification is not unequivocal in intellectually able individuals (Bastiaansen et al. 2011a; Pugliese et al. 2015; Ring et al. 2015), we included all these ASD participants in the current study. Furthermore, $80 \%$ scored above the threshold of 26 on the AQ (Woodbury-Smith et al. 2005). All individuals had a Mini Mental State Examination score above 26 (Folstein et al. 1975). Hence, with respect to Part II, the final sample for the examination of co-occurring disorders was composed of 138 ASD participants and 170 COM participants.

Based on a tertile split of this ASD group, the participants were assigned to a young (19-38 years), middle-aged (39-54 years), and older (55-79 years) adult group (Table 1). Please note that information about diagnostic status, medical conditions, and medication usage was obtained by means of self-report.

\section{Measures}

\section{Psychiatric Co-occurring Symptoms}

Symptom Checklist-90 Revised (SCL-90-R) The SCL-90R (Arrindell and Ettema 2005; Derogatis 1977) is a widely used multidimensional self-report inventory consisting of 90 items to assess the presence of current psychopathological symptoms and psychological distress. Each item is rated on a five-point Likert scale ranging from 0 "not at all" to 4 "very much" and indicates how much distress was caused during the last week comprising today. The original SCL-90-R includes nine primary symptom dimensions and three global indices that cover clinically relevant psychiatric and psychosomatic symptoms. The Dutch version (Arrindell and Ettema 2005), however, measures eight dimensions: anxiety, agoraphobia, depression, somatization, cognitive-performance deficits, interpersonal sensitivity and mistrust, hostility, and sleep difficulties. The total score, psychoneuroticism, provides a general measure of psychological distress. Higher scores indicate more symptoms and distress. The psychometric properties of the SCL-90-R, including internal consistency, test-retest reliability, and convergent and divergent validity, are good to very good (Arrindell and Ettema 2005). 
Table 1 Descriptives of the ASD and COM group for Part I and II

\begin{tabular}{|c|c|c|c|c|c|c|c|c|c|c|c|}
\hline & \multicolumn{4}{|l|}{ ASD } & \multirow{2}{*}{$\begin{array}{l}\text { Young versus } \\
\text { middle versus } \\
\text { older } \\
\text { Fisher's } \chi^{2} \\
\text { or } F\end{array}$} & \multicolumn{4}{|c|}{$\mathrm{COM}$} & \multirow{2}{*}{$\begin{array}{l}\text { Young versus } \\
\text { middle versus } \\
\text { older } \\
\text { Fisher's } \chi^{2} \text { or } \\
F\end{array}$} & \multirow{2}{*}{$\begin{array}{l}\text { ASD } \\
\text { versus } \\
\text { COM } \\
\chi^{2}\end{array}$} \\
\hline & $\begin{array}{l}\text { All } \\
\text { ages }\end{array}$ & Young & Middle & Older & & $\begin{array}{l}\text { All } \\
\text { ages }\end{array}$ & Young & Middle & Older & & \\
\hline \multicolumn{12}{|l|}{ Part I } \\
\hline $\mathrm{N}$ & 172 & 52 & 72 & 48 & & 172 & 60 & 47 & 65 & & \\
\hline Gender & & & & & 4.27 & & & & & 1.75 & $4.45^{*}$ \\
\hline Male & 116 & 33 & 45 & 38 & & 97 & 37 & 23 & 37 & & \\
\hline Female & 56 & 19 & 27 & 10 & & 75 & 23 & 24 & 28 & & \\
\hline Education $^{\mathrm{a}}$ & & & & & 11.98 & & & & & $15.14^{+}$ & $9.77^{+}$ \\
\hline Low & 1 & 0 & 1 & 0 & & 0 & 0 & 0 & 0 & & \\
\hline Middle & 55 & 18 & 19 & 18 & & 37 & 9 & 10 & 18 & & \\
\hline High & 115 & 34 & 51 & 30 & & 134 & 51 & 37 & 46 & & \\
\hline Diagnosis & & & & & 6.71 & & & & & - & - \\
\hline Autistic disorder & 26 & 5 & 12 & 9 & & - & - & - & - & & \\
\hline Asperger & 88 & 27 & 35 & 26 & & - & - & - & - & & \\
\hline PDD-NOS & 53 & 16 & 24 & 13 & & - & - & - & - & & \\
\hline ASD & 5 & 4 & 1 & 0 & & - & - & - & - & & \\
\hline ISCO & & & & & $19.29 * *$ & & & & & $49.93 * * *$ & $7.70^{+}$ \\
\hline Class 1-3 & 62 & 11 & 37 & 14 & & 80 & 19 & 36 & 25 & & \\
\hline Class 4-6 & 21 & 8 & 10 & 3 & & 22 & 13 & 5 & 4 & & \\
\hline Class 7-9 & 11 & 2 & 4 & 5 & & 4 & 4 & 0 & 0 & & \\
\hline Unemployed & 74 & 30 & 20 & 24 & & 57 & 23 & 1 & 33 & & \\
\hline Age (mean) & 46.7 & 29.3 & 47.9 & 63.7 & $525.52 * * *$ & 46.0 & 26.8 & 47.0 & 63.0 & $711.07 * * *$ & 0.16 \\
\hline AQ (mean) & 33.5 & 32.1 & 34.4 & 33.4 & 1.16 & 12.4 & 12.3 & 11.1 & 13.0 & 1.77 & $831.22 * * *$ \\
\hline IQ (mean) & NA & NA & NA & NA & & NA & NA & NA & NA & & \\
\hline MMSE (mean) & NA & NA & NA & NA & & NA & NA & NA & NA & & \\
\hline ADOS (mean) & NA & NA & NA & NA & & - & - & - & - & & \\
\hline Psychotropic medication & 87 & 28 & 38 & 21 & 1.26 & 6 & 0 & 2 & 4 & 3.75 & $96.69 * * *$ \\
\hline Antidepressants ${ }^{\mathrm{b}}$ & 52 & 18 & 23 & 11 & 1.80 & 4 & 0 & 1 & 3 & $2.61^{+}$ & $49.14 * * *$ \\
\hline $\begin{array}{l}\text { Anxiolytic/sedative/ } \\
\text { hypnotics }\end{array}$ & 19 & 6 & 8 & 5 & 0.10 & 1 & 0 & 0 & 1 & 1.61 & $17.20 * * *$ \\
\hline Antipsychotics & 24 & 14 & 7 & 3 & $9.62 * *$ & 0 & 0 & 0 & 0 & - & $25.80 * * *$ \\
\hline Stimulants & 14 & 4 & 8 & 2 & 1.73 & 0 & 0 & 0 & 0 & - & $14.59 * * *$ \\
\hline $\begin{array}{l}\text { Other psychotropic } \\
\text { medication }\end{array}$ & 11 & 1 & 8 & 2 & 4.22 & 1 & 0 & 1 & 0 & 2.25 & $8.64 * *$ \\
\hline $\begin{array}{l}\text { Other non-psychotropic } \\
\text { medication }\end{array}$ & 58 & 9 & 27 & 22 & $10.23 * *$ & 55 & 6 & 15 & 34 & $27.04 * * *$ & 0.12 \\
\hline \multicolumn{12}{|l|}{ Part II } \\
\hline $\mathrm{N}$ & 138 & 46 & 47 & 45 & & 170 & 60 & 46 & 64 & & \\
\hline Gender & & & & & 3.83 & & & & & 1.47 & $5.09 *$ \\
\hline Male & 96 & 31 & 29 & 36 & & 97 & 37 & 23 & 37 & & \\
\hline Female & 42 & 15 & 18 & 9 & & 73 & 23 & 23 & 27 & & \\
\hline Education $^{\mathrm{a}}$ & & & & & 10.77 & & & & & $13.49^{+}$ & $8.50^{+}$ \\
\hline Low & 1 & 0 & 1 & 0 & & 0 & 0 & 0 & 0 & & \\
\hline Middle & 43 & 15 & 11 & 17 & & 36 & 9 & 9 & 18 & & \\
\hline High & 94 & 31 & 35 & 28 & & 134 & 51 & 37 & 46 & & \\
\hline Diagnosis & & & & & 6.82 & & & & & - & - \\
\hline Autistic disorder & 21 & 4 & 9 & 8 & & - & - & - & - & & \\
\hline Asperger & 69 & 24 & 21 & 24 & & - & - & - & - & & \\
\hline
\end{tabular}


Table 1 continued

\begin{tabular}{|c|c|c|c|c|c|c|c|c|c|c|c|}
\hline & \multicolumn{4}{|l|}{ ASD } & \multirow{2}{*}{$\begin{array}{l}\text { Young versus } \\
\text { middle versus } \\
\text { older } \\
\text { Fisher's } \chi^{2} \\
\text { or } F\end{array}$} & \multicolumn{4}{|l|}{$\mathrm{COM}$} & \multirow{2}{*}{$\begin{array}{l}\text { Young versus } \\
\text { middle versus } \\
\text { older } \\
\text { Fisher's } \chi^{2} \text { or } \\
F\end{array}$} & \multirow{2}{*}{$\begin{array}{l}\text { ASD } \\
\text { versus } \\
\text { COM } \\
\chi^{2}\end{array}$} \\
\hline & $\begin{array}{l}\text { All } \\
\text { ages }\end{array}$ & Young & Middle & Older & & $\begin{array}{l}\text { All } \\
\text { ages }\end{array}$ & Young & Middle & Older & & \\
\hline PDD-NOS & 43 & 14 & 16 & 13 & & - & - & - & - & & \\
\hline ASD & 5 & 4 & 1 & 0 & & - & - & - & - & & \\
\hline ISCO & & & & & $14.98^{*}$ & & & & & $48.84 * * *$ & $7.37^{+}$ \\
\hline Class 1-3 & 48 & 10 & 25 & 13 & & 79 & 19 & 35 & 25 & & \\
\hline Class 4-6 & 16 & 7 & 6 & 3 & & 22 & 13 & 5 & 4 & & \\
\hline Class 7-9 & 6 & 1 & 1 & 4 & & 4 & 4 & 0 & 0 & & \\
\hline Unemployed & 66 & 27 & 15 & 24 & & 57 & 23 & 1 & 33 & & \\
\hline Age (mean) & 46.5 & 28.8 & 47.2 & 63.9 & $481.64 * * *$ & 45.9 & 26.8 & 47.2 & 62.9 & $703.46^{* * *}$ & 0.11 \\
\hline AQ (mean) & 33.5 & 31.7 & 35.2 & 33.4 & 2.06 & 12.2 & 12.3 & 11.0 & 13.0 & 1.83 & $723.60 * * *$ \\
\hline IQ (mean) & 113.8 & 112.1 & 116.7 & 112.5 & 1.10 & 113.3 & 111.2 & 114.1 & 114.8 & 0.78 & 0.06 \\
\hline MMSE (mean) & 29.0 & 28.9 & 29.1 & 29.1 & 0.57 & 29.1 & 29.3 & 29.1 & 29.0 & 1.41 & 0.71 \\
\hline ADOS (mean) & 8.6 & 9.5 & 8.5 & 8.0 & $2.43^{+}$ & - & - & - & - & - & - \\
\hline Psychotropic medication & 67 & 22 & 27 & 18 & 2.80 & 6 & 0 & 2 & 4 & 3.82 & $85.37 * * *$ \\
\hline Antidepressants ${ }^{\mathrm{b}}$ & 38 & 12 & 16 & 10 & 1.65 & 4 & 0 & 1 & 3 & 2.65 & $41.02 * * *$ \\
\hline $\begin{array}{l}\text { Anxiolytic/sedative/ } \\
\text { hypnotics }\end{array}$ & 16 & 5 & 6 & 5 & 0.17 & 1 & 0 & 0 & 1 & 1.62 & $17.69 * * *$ \\
\hline Antipsychotics & 18 & 11 & 4 & 3 & $6.46^{*}$ & 0 & 0 & 0 & 0 & - & $23.55 * * *$ \\
\hline Stimulants & 9 & 4 & 4 & 1 & 2.11 & 0 & 0 & 0 & 0 & - & $11.42 * * *$ \\
\hline $\begin{array}{l}\text { Other psychotropic } \\
\text { medication }\end{array}$ & 9 & 1 & 7 & 1 & $6.73 * *$ & 1 & 0 & 1 & 0 & 2.28 & $8.54 * *$ \\
\hline $\begin{array}{l}\text { Other non-psychotropic } \\
\text { medication }\end{array}$ & 46 & 7 & 20 & 19 & $10.73 * *$ & 53 & 6 & 14 & 33 & $26.08 * * *$ & 0.16 \\
\hline
\end{tabular}

$A S D$ autism spectrum disorder, COM comparison group, $P D D-N O S$ pervasive developmental disorder not otherwise specified, ISCO International Standard Classification of Occupations, $A Q$ Autism-Spectrum Quotient, $I Q$ estimated intelligence quotient, MMSE Mini Mental State Examination, ADOS Autism Diagnostic Observation Schedule

${ }^{a}$ One missing in both groups

b Antidepressant medication refers to the use of non-selective monoamine reuptake inhibitors, selective serotonin reuptake inhibitors, and other antidepressants

$+p<.1 ; * p \leq .05 ; * * p \leq .01 ; * * * p \leq .001$

\section{Psychiatric Co-occurring Disorders}

Mini International Neuropsychiatric Interview Plus (MINIPlus) The MINI-Plus (Sheehan et al. 1998; van Vliet et al. 2000) is a structured diagnostic interview that explores several psychiatric disorders according to DSMIV criteria. First, two to four screenings questions are asked for each disorder. Second, if any of these is answered positively, additional questions further inquire about the presence of a disorder. We inquired about mood, anxiety, substance-related, eating, somatoform, and conduct disorders. The MINI has good inter-rater and test-retest reliability (Lecrubier et al. 1997; Sheehan et al. 1997). For the current study, we adjusted wording of a small number of questions, for example by splitting extended questions into sub questions, to make them more comprehensible to individuals with ASD and to be able of examining lifetime adherence for all disorders. Although we did not change the purport of the items, the validity of the MINI may have been reduced due to these adjustments.

ADHD Rating Scale The ADHD rating scale (Kooij et al. 2005 ) is a 23 -item self-report questionnaire to assess ADHD symptoms based on DSM-IV criteria. Using the adult scale, an individual rates the extent to which each statement illustrates his or her behavior over the past 6 months on a four-point Likert scale, ranging from 0 "rarely or never" to 3 "very often". Items rated with "often" or "very often" met diagnostic criteria for either inattentive or hyperactive-impulsive subtype symptoms. 
Following the DSM-IV (American Psychiatric Association 2000), we considered the presence of at least six out of nine symptoms per subtype as indicative of an $\mathrm{AD}(\mathrm{H}) \mathrm{D}$ diagnosis. The validity of the ADHD rating scale is reasonable (Kooij et al. 2008).

\section{Risk Factors}

ASD severity as measured with the AQ and ADOS, intellectual functioning (IQ) as estimated with a short version of the WAIS-III, general cognitive functioning as measured with the MMSE, and information on education, work situation (coded according to the International Standard Classification of Occupations [ISCO]), living situation, gender, and age as indicated by self-report constituted the factors that were considered as being potentially predictive of psychopathology.

\section{Procedure}

Informed consent was obtained from all individual participants included in the study, after which they filled out the AQ and SCL-90, among other questionnaires (Part I). Participants selected for Part II were tested in two sessions during which (1) the ADOS, shortened WAIS-III, MMSE, and MINI were administered, and (2) neuropsychological and experimental testing took place (these are described elsewhere) (e.g., Lever \& Geurts 2015a). Participants who were tested in at least one test session received compensation for their travel expenses; most COM participants also received additional compensation $(\max € 20$ ). The study was approved by the institutional review board of the University of Amsterdam and was in accordance with the 1964 Helsinki declaration and its later amendments or comparable ethical standards.

\section{Statistical Analyses}

\section{Psychiatric Co-occurring Symptoms}

SCL-90-R variables were highly skewed and neither log, square root, nor inverse transformation lead to normality. However, as MANOVA is thought be robust against this type of violation (Stevens 2012), we ran a MANOVA with Diagnostic group (ASD, COM) and Age (young, middleaged, older) as between-subject factors and the total score and SCL-90-R subscales as dependent variables. Raw scores were then compared with normative data available for the general population and a policlinic psychiatric patient group (Arrindell and Ettema 2005). Analyses were run with and without outliers (data points more than $3 \mathrm{SD}$ from group mean). When the pattern of results changed by removing outliers, we report both analyses.

\section{Psychiatric Co-occurring Disorders}

Chi square tests were used to compare frequencies of psychiatric disorders, as measured with the MINI-Plus and ADHD list, between the ASD and COM group. We clustered the inquired disorders into six major disorders: mood, anxiety, substance-related, eating, somatoform, and attentional and behavioral disorders and Bonferroni corrected for multiple comparisons (i.e., significance level was set on $0.05 / 6=0.0083$ ). Thereafter, Chi square tests were ran per non-clustered disorder to compare the ASD and COM group and Fisher's exact test was used to compare frequencies between young, middle-aged and older adults per diagnostic group. No further correction was applied to these analyses. Results per distinct disorder are presented when group differences were significant after Bonferroni correction. Otherwise, they are presented in the supplementary material (Online Resource 1).

\section{Risk Factors}

Binomial logistic regressions and linear regressions were run to assess the association between potential risk factors and any mood or anxiety disorder and depression and anxiety symptoms, respectively. Please note that we computed these risk factor analyses on the sample of Part II (due to the inclusion of IQ and ADOS) and that we excluded the COM group from these analyses (as our focus was on risk factors involved in the ASD group). All analyses were conducted in SPSS 22.0 (IBM Corp. 2013).

\section{Results}

\section{Psychiatric Co-occurring Symptoms}

The SCL-90-R scores for Part I are presented in Table 2. The omnibus MANOVA revealed a main effect of diagnostic group, $\Lambda=0.58, F(9,330)=26.42, p<.001$, $\eta_{\mathrm{p}}^{2}=.42$, but no main effect of age-group, $\Lambda=0.96, F(18$, $660)=0.82, p=.672, \eta_{\mathrm{p}}^{2}=.02$, nor an interaction effect, $\Lambda=0.94, F(18,660)=1.15, p=.298, \eta_{\mathrm{p}}^{2}=.03$. The ASD group had higher scores on all subscales and the total score. This is in line with the findings when we compare the scores of the ASD sample to the norms of a general population sample as over a quarter of adults with ASD had depression or anxiety scores that were considered very high ( $\geq 95$ th percentile). However, compared to a psychiatric patient group, only a few individuals $(<5 \%)$ with ASD had scores above the 95th percentile (Table 3), which suggest that these high scores for individuals with ASD are common in individuals with psychiatric diagnoses. 
Table 2 SCL-90-R total and subscale scores for the young, middle-aged, and older adults with and without ASD

\begin{tabular}{|c|c|c|c|c|c|c|c|c|c|c|}
\hline & \multicolumn{4}{|l|}{ ASD } & \multicolumn{4}{|l|}{$\mathrm{COM}$} & \multicolumn{2}{|c|}{ ASD versus $\mathrm{COM}^{\mathrm{a}}$} \\
\hline & All ages & Young & Middle & Older & All ages & Young & Middle & Older & $F$ & $\eta_{p}^{2}$ \\
\hline Psychoneuroticism & 174.9 & 183.9 & 173.1 & 167.6 & 113.3 & 111.3 & 115.9 & 113.2 & $192.96 * * *$ & .36 \\
\hline Agoraphobia & 11.4 & 12.2 & 11.3 & 10.6 & 7.4 & 7.3 & 7.2 & 7.5 & $116.89 * * *$ & .26 \\
\hline Anxiety & 18.3 & 19.8 & 18.1 & 17.0 & 11.8 & 11.4 & 12.1 & 11.8 & $111.28 * * *$ & .25 \\
\hline Depression & 33.6 & 34.8 & 33.9 & 31.8 & 20.6 & 19.8 & 21.1 & 21.0 & $151.71 * * *$ & .31 \\
\hline Somatization & 20.5 & 21.6 & 20.8 & 18.9 & 15.3 & 15.4 & 15.5 & 15.1 & $62.81 * * *$ & .16 \\
\hline Cognitive-performance deficits & 21.1 & 21.7 & 21.1 & 20.5 & 12.5 & 12.7 & 12.7 & 12.2 & $208.91 * * *$ & .38 \\
\hline Interpersonal sensitivity and mistrust & 37.2 & 38.8 & 36.1 & 37.2 & 23.4 & 22.7 & 24.3 & 23.3 & $152.44 * * *$ & .31 \\
\hline Hostility & 9.9 & 10.8 & 9.5 & 9.3 & 7.0 & 7.1 & 7.2 & 6.8 & $83.57 * * *$ & .20 \\
\hline Sleep difficulties & 6.6 & 6.9 & 6.7 & 6.2 & 4.7 & 4.6 & 4.7 & 4.8 & $43.21 * * *$ & .11 \\
\hline
\end{tabular}

$A S D$ autism spectrum disorder, COM comparison group

${ }^{a}$ We do not report the effects of age-group as the overall MANOVA revealed a nonsignificant effect, as denoted in the main text

Table 3 Number (\%) of adults with and without ASD scoring above the 95th percentile compared to a normative general population and a psychiatric patient sample

\begin{tabular}{|c|c|c|c|c|}
\hline & \multicolumn{2}{|l|}{ ASD } & \multicolumn{2}{|l|}{$\mathrm{COM}$} \\
\hline & NOR & PSY & NOR & PSY \\
\hline Psychoneuroticism & $69(40.1 \%)$ & $3(1.7 \%)$ & $5(2.9 \%)$ & $0(-)$ \\
\hline Agoraphobia & $79(45.9 \%)$ & $1(0.8 \%)$ & $2(1.2 \%)$ & $0(-)$ \\
\hline Anxiety & $44(25.6 \%)$ & $1(0.8 \%)$ & $2(1.2 \%)$ & $0(-)$ \\
\hline Depression & $70(40.7 \%)$ & $1(0.8 \%)$ & $5(2.9 \%)$ & $0(-)$ \\
\hline Somatization & $29(16.9 \%)$ & $3(1.7 \%)$ & $3(1.7 \%)$ & $0(-)$ \\
\hline Cognitive-performance deficits & $87(50.6 \%)$ & $5(2.9 \%)$ & $6(3.5 \%)$ & $0(-)$ \\
\hline Interpersonal sensitivity and mistrust & $67(39.0 \%)$ & $8(4.7 \%)$ & $9(5.2 \%)$ & $0(-)$ \\
\hline Hostility & $51(29.7 \%)$ & $3(1.7 \%)$ & $6(3.5 \%)$ & $0(-)$ \\
\hline Sleep difficulties & $42(24.4 \%)$ & $4(2.3 \%)$ & $10(5.8 \%)$ & $0(-)$ \\
\hline
\end{tabular}

$A S D$ autism spectrum disorder, COM comparison group, NOR general population; $P S Y$ psychiatric patient sample

When running the MANOVA on the subgroup sample of Part II, there was still a main effect of diagnostic group and no main effect of age-group, but now the diagnostic group by age-group interaction was significant, $\Lambda=0.88, F(18$, $588)=2.16, p=.004, \eta_{\mathrm{p}}^{2}=.06$, with generally a decrease of reported symptoms with age in the ASD group and no such a decrease in the COM group. After removing the outliers, in addition to the already present effects, there was also a main effect of age-group, $\Lambda=0.88, \quad F(18$, $542)=1.95, p=.011, \eta_{\mathrm{p}}^{2}=.06$. The older age group generally had lower scores than the younger groups, even though this difference seemed more pronounced in the ASD group.

\section{Psychiatric Co-occurring Disorders}

The frequencies of the investigated lifetime DSM-IV diagnoses are presented in Table 4. In the ASD group,
$79.0 \%$ met one or more lifetime diagnosis for a psychiatric disorder against $48.8 \%$ of the COM group. Overall, older adults with ASD less often met diagnostic criteria compared to the younger age groups, whereas there were no differences between age groups among adults without ASD. In the ASD group, while $21 \%$ did not meet criteria for any psychiatric diagnoses and $20.3 \%$ met criteria for one psychopathology, over $57 \%$ had more than one cooccurring lifetime disorder. In the COM group, the large majority did meet criteria for one or none lifetime DSM-IV diagnosis. Nevertheless, a small percentage $(15.9 \%)$ of the individuals without ASD had more than one co-occurring psychopathology (Table 5).

As expected, in adults with ASD, mood disorders were the most common group of psychiatric disorders (57.2\%) and included major depression $(53.6 \%)$ and dysthymia $(18.1 \%)$. Mood disorders were most prevalent in middleaged adults and least prevalent in the oldest age-group with 


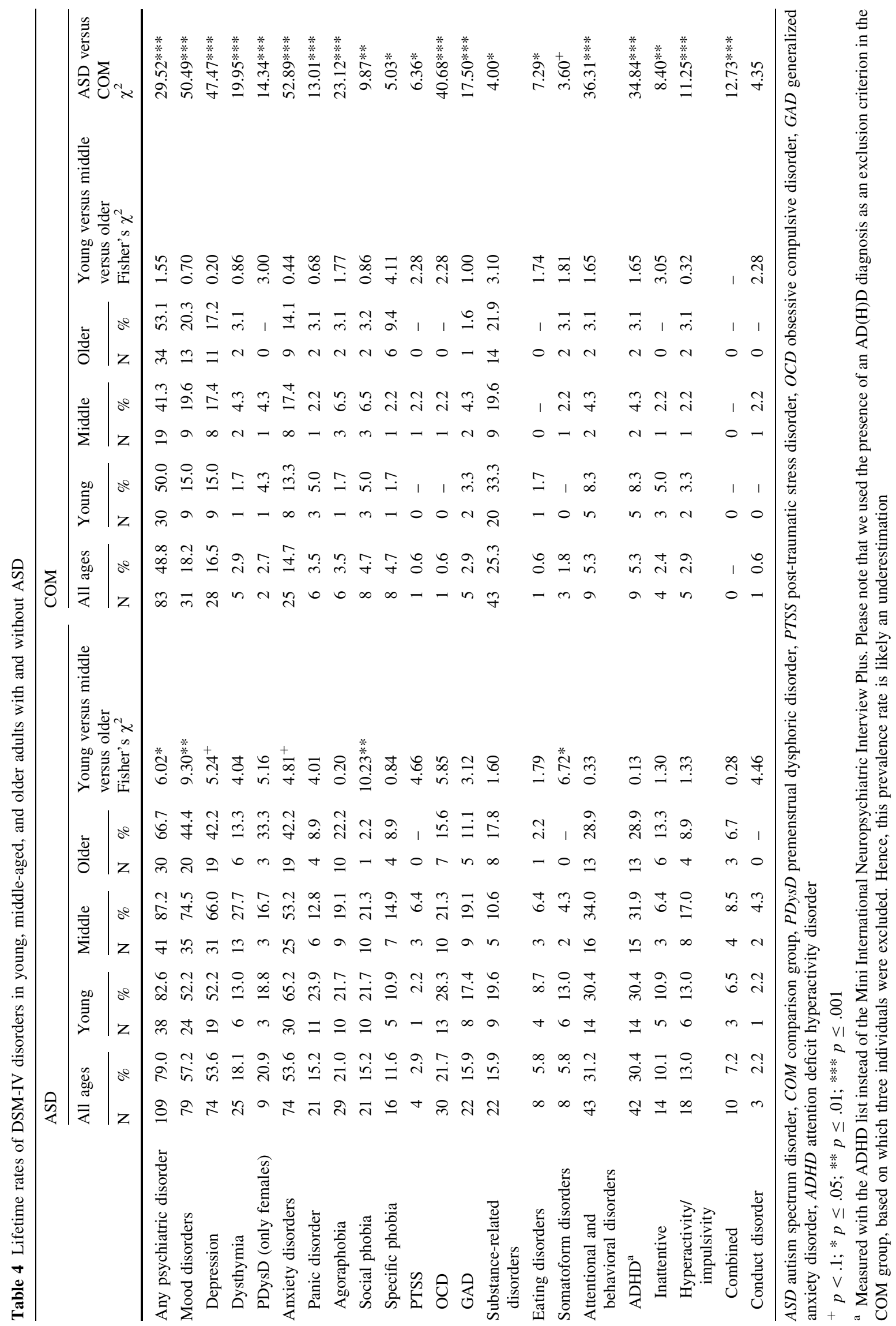


Table 5 Frequencies and percentages of the number of lifetime diagnoses in young, middle-aged, and older adults with and without ASD

\begin{tabular}{|c|c|c|c|c|c|c|c|c|c|c|c|c|c|c|c|c|}
\hline & \multicolumn{8}{|c|}{ ASD } & \multicolumn{8}{|c|}{$\mathrm{COM}$} \\
\hline & \multicolumn{2}{|c|}{ All ages } & \multicolumn{2}{|c|}{ Young } & \multicolumn{2}{|c|}{ Middle } & \multicolumn{2}{|c|}{ Older } & \multicolumn{2}{|c|}{ All ages } & \multicolumn{2}{|c|}{ Young } & \multicolumn{2}{|c|}{ Middle } & \multicolumn{2}{|c|}{ Older } \\
\hline & $\mathrm{N}$ & $\%$ & $\mathrm{~N}$ & $\%$ & $\mathrm{~N}$ & $\%$ & $\mathrm{~N}$ & $\%$ & $\mathrm{~N}$ & $\%$ & $\mathrm{~N}$ & $\%$ & $\mathrm{~N}$ & $\%$ & $\mathrm{~N}$ & $\%$ \\
\hline No DSM-IV diagnoses & 29 & 21.0 & 8 & 17.4 & 6 & 12.8 & 15 & 33.3 & 87 & 51.2 & 30 & 50.0 & 27 & 58.7 & 30 & 46.9 \\
\hline 1 DSM-IV diagnosis & 28 & 20.3 & 6 & 13.0 & 13 & 27.7 & 9 & 20.0 & 56 & 32.9 & 16 & 26.7 & 13 & 28.3 & 27 & 42.2 \\
\hline 2 DSM-IV diagnoses & 19 & 13.8 & 8 & 17.4 & 7 & 14.9 & 4 & 8.9 & 16 & 9.4 & 8 & 13.3 & 3 & 6.5 & 5 & 7.8 \\
\hline 3 DSM-IV diagnoses & 24 & 17.4 & 8 & 17.4 & 6 & 12.8 & 10 & 22.2 & 4 & 2.4 & 2 & 3.3 & 1 & 2.2 & 1 & 1.6 \\
\hline 4 DSM-IV diagnoses & 17 & 12.3 & 9 & 19.6 & 3 & 6.4 & 5 & 11.1 & 2 & 1.2 & 2 & 3.3 & 0 & - & 0 & - \\
\hline$>4$ DSM-IV diagnoses & 21 & 15.2 & 7 & 15.2 & 12 & 25.5 & 2 & 4.4 & 5 & 2.9 & 2 & 3.3 & 2 & 4.3 & 1 & 1.6 \\
\hline
\end{tabular}

$A S D$ autism spectrum disorder, COM comparison group

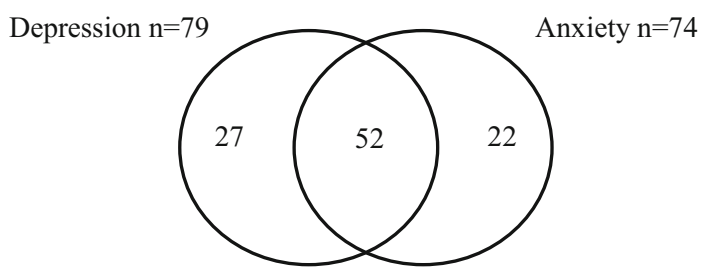

Fig. 1 Number of ASD participants showing overlap between mood and anxiety disorders

ASD. All mood disorders were more frequent in adults with ASD than in adults without ASD. There were no differences between age-groups in the COM group.

The second most common group of disorders in the ASD group were the anxiety disorders $(53.6 \%)$ of which obsessive-compulsive disorder (OCD; $21.7 \%$ ) and agoraphobia $(21.0 \%)$ most often occurred. The prevalence of any anxiety disorder appeared slightly lower in older adults, but it was not statistically significant. Whereas social phobia was common in young and middle-aged adults, it was not in older adults with ASD. All anxiety disorders were more frequent in adults with ASD than in adults without ASD. In the COM group, there were no differences between age-groups.

As mood and anxiety disorders often co-occur (Beekman et al. 2000; Sartorius et al. 1996), we explored the overlap between these two lifetime diagnoses (Fig. 1). Over $65 \%$ of the adults with ASD meeting criteria for any lifetime mood or anxiety disorder, also met criteria for the other co-occurring disorder.

\section{Associations Between Potential Risk Factors and Mood and Anxiety Symptoms}

ASD severity by both self-report and ADOS was predictive of the amount of depression and anxiety symptoms as measured with the SCL-90-R. None of the other factors was significantly associated with these symptoms (Table 6).

\section{Associations Between Potential Risk Factors and any Mood and Anxiety Disorder}

Female gender was a significant predictor of any mood disorder. Lower age and more severe ASD as indicated by self-report were associated with the presence of any anxiety disorder. None of the other factors was associated with any mood or anxiety disorder (Table 7 ).

\section{Discussion}

In the current study, we examined psychiatric symptoms and disorders in young, middle-aged, and older adults with ASD and focused on the two most frequently occurring diagnoses (i.e., mood and anxiety) by testing several potential risk factors covering different domains. As expected, adults with ASD experienced more psychological symptoms and distress compared to a typically developing comparison group. These elevated levels were not only reported by older adults (for similar findings see van Heijst and Geurts 2014), but were consistently high also in young and middle-aged adults and, thus, across the adult lifespan. Whereas at least a quarter of the adults with ASD reported symptoms within the clinical range compared to a population-based sample, only a few participants scored within the clinical range when compared to a psychiatric patient group (see also Joshi et al. 2013). These findings indicate that, as expected, adults with ASD experience many feelings of depression, anxiety, and psychological distress, but this was not atypical when compared to other psychiatric patients.

Consistent with the experience of many psychological symptoms, is the high proportion of individuals meeting criteria for a psychiatric diagnosis. Seventy-nine percent of the adults with ASD have experienced any psychiatric disorder once in their lives. As predicted, most common disorders were mood $(57 \%)$ and anxiety disorders (54\%), 
Table 6 Risk factors associated with depression and anxiety symptoms (SCL-90-R) in adults with ASD

\begin{tabular}{|c|c|c|c|c|c|c|c|c|}
\hline & \multicolumn{4}{|c|}{ Depression } & \multicolumn{4}{|l|}{ Anxiety } \\
\hline & B & SE & $\mathrm{t}$ & $95 \% \mathrm{CI}$ & $\mathrm{B}$ & SE & $\mathrm{t}$ & $95 \% \mathrm{CI}$ \\
\hline Age & -0.05 & 0.07 & -0.75 & -0.18 to 0.08 & -0.10 & 0.06 & -1.62 & -0.23 to 0.02 \\
\hline Gender & 4.24 & 2.33 & 1.82 & -0.37 to 8.84 & 3.85 & 2.25 & 1.71 & -0.61 to 8.31 \\
\hline Education & -1.98 & 2.23 & -0.89 & -6.40 to 2.44 & -3.04 & 2.16 & -1.41 & -7.31 to 1.24 \\
\hline Living situation & -0.53 & 1.06 & -0.50 & -2.63 to 1.58 & -0.93 & 1.03 & -0.91 & -2.97 to 1.10 \\
\hline ISCO & 0.05 & 0.73 & 0.07 & -1.38 to 1.49 & 0.43 & 0.70 & 0.62 & -0.96 to 1.83 \\
\hline IQ & -0.06 & 0.07 & -0.93 & -0.19 to 0.07 & 0.01 & 0.06 & 0.18 & -0.11 to 0.14 \\
\hline MMSE & -0.57 & 1.04 & -0.55 & -2.63 to 1.49 & -1.39 & 1.01 & -1.38 & -3.39 to 0.60 \\
\hline AQ & 0.45 & 0.12 & $3.62 * * *$ & 0.20 to 0.69 & 0.40 & 0.12 & $3.33 * * *$ & 0.16 to 0.63 \\
\hline ADOS & 0.89 & 0.34 & $2.66 * *$ & 0.23 to 1.56 & 0.77 & 0.33 & $2.38 *$ & 0.13 to 1.42 \\
\hline Constant & 36.94 & 28.45 & 1.30 & -19.37 to 93.26 & 57.94 & 27.54 & $2.10^{*}$ & 3.44 to 112.45 \\
\hline $\mathrm{R}^{2}$ & $20.5 \%$ & & & & $20.9 \%$ & & & \\
\hline $\mathrm{N}$ & 134 & & & & 134 & & & \\
\hline
\end{tabular}

SCL-90-R Symptom Checklist 90 revised, ISCO International Standard Classification of Occupations, IQ estimated intelligence quotient, $M M S E$ Mini Mental State Examination, $A Q$ Autism-spectrum Quotient, $A D O S$ Autism Diagnostic Observation Schedule

$* p \leq .05 ; * * p \leq .01 ; * * * p \leq .001$

which often co-occur. ADHD frequently occurred as well $(30 \%)$ and notable is the high percentage of females meeting criteria for a premenstrual dysphoric disorder $(21 \%)$. The estimated occurrences of psychiatric disorders in a large group of adults with ASD is comparable to those previously reported in other studies of adults without IDs using the Structured Clinical Interview for DSM-IV axis I Disorders (SCID-I) or a structured DSM-IV based clinical interview (Hofvander et al. 2009; Lugnegård et al. 2011; Roy et al. 2015). The MINI is based on both the DSM-IV and ICD-10 (Lecrubier et al. 1997) and the MINI and SCID-I are well concordant with each other (Sheehan et al. 1997). Given the consistency with previous studies involving a similar population, the current findings seem to reflect the true lifetime psychiatric problems of adults with ASD.

However, while others focused on young and middleaged adults, we also examined older adults and we found that, also in late adulthood, psychiatric disorders were still common. Nevertheless, lifetime diagnoses for any psychiatric disorder were less often present in older than in younger adults with ASD, suggesting reduced psychopathology in late adulthood, a pattern that has been commonly observed in large typical aging studies (Bijl et al. 1998; Kessler et al. 2005). Although a recent study found the opposite (i.e., psychopathology was more common in older than in younger adults) in older adults with ASD and without ID (Roy et al. 2015), this seems mainly due to the inclusion of middle-aged adults in the "older" adult group (age range 40-62 years) in the study of Roy and colleagues. Especially in mid adulthood, psychiatric disorders such as depression seem more common than in older or younger individuals (Bijl et al. 1998; Kessler et al. 2005). While our older adult group consisted of participants until 79 years of age, participants in the Roy study were rather middle-aged, which would explain why high rates were found and why our findings were apparently discordant. We also observed that only one $(2 \%)$ older adult met criteria for social phobia (i.e., social anxiety disorder) against $21 \%$ of young and middle-aged adults. Of course, this could be due to a cohort effect. However, there are several potential alternative explanations for this latter finding. First, social phobia and social skills may reciprocally influence each other: individuals with poor social skills may be more likely to experience anxiety related to social interactions, but, inversely, individuals with social anxiety may less likely develop and practice their social skills (Bellini 2004). In fact, adults with social anxiety disorder report difficulties in social skills, similarly to ASD individuals (Cath et al. 2008). Although social symptoms tend to remain stable over time in ASD (Magiati et al. 2014), social functioning seems to improve (Bastiaansen et al. 2011b). Older adults would be more able to adjust their behavior to social situations and cope with their social difficulties, which could have a positive effect on feeling more comfortable in social situations and a negative effect on feelings of anxiety. Second, reduced social anxiety can be associated with a decrement in awareness or concern about social situations, for example due to lower empathic skills (Bellini 2004). However, neither empathic concern (Lever and Geurts 2015b) nor theory of mind (Lever and Geurts 2015a) declined in older adults with ASD, suggesting that this explanation does not hold. Third, older adults may have accepted their difficulties in social 
Table 7 Risk factors associated with any mood and anxiety disorder (MINI-Plus) in adults with ASD

\begin{tabular}{|c|c|c|c|c|c|c|c|c|}
\hline & \multicolumn{4}{|c|}{ Any mood disorder } & \multicolumn{4}{|c|}{ Any anxiety disorder } \\
\hline & B & SE & Odds Ratio & $95 \% \mathrm{CI}$ & B & SE & Odds Ratio & $95 \%$ CI \\
\hline Age & -0.00 & 0.01 & 1.00 & 0.97 to 1.02 & -0.04 & 0.02 & $0.97 *$ & 0.94 to 1.00 \\
\hline Gender & 1.46 & 0.49 & $4.29 * *$ & 1.65 to 11.18 & 0.85 & 0.52 & 2.33 & 0.85 to 6.42 \\
\hline Education & -0.14 & 0.44 & 0.87 & 0.37 to 2.04 & -0.67 & 0.50 & 0.51 & 0.19 to 1.37 \\
\hline Living situation & 0.18 & 0.21 & 1.20 & 0.80 to 1.80 & 0.04 & 0.23 & 1.05 & 0.67 to 1.64 \\
\hline ISCO & -0.14 & 0.14 & 0.87 & 0.66 to 1.15 & 0.09 & 0.16 & 1.09 & 0.80 to 1.48 \\
\hline IQ & -0.00 & 0.01 & 1.00 & 0.97 to 1.02 & -0.01 & 0.01 & 0.99 & 0.96 to 1.02 \\
\hline MMSE & -0.03 & 0.20 & 0.97 & 0.66 to 1.43 & 0.00 & 0.23 & 1.00 & 0.65 to 1.56 \\
\hline AQ & 0.01 & 0.02 & 1.01 & 0.97 to 1.06 & 0.15 & 0.03 & $1.16^{* * *}$ & 1.09 to 1.24 \\
\hline ADOS & 0.02 & 0.07 & 1.02 & 0.90 to 1.16 & 0.04 & 0.07 & 1.04 & 0.90 to 1.20 \\
\hline Constant & -0.56 & 5.42 & 0.57 & & -2.18 & 6.07 & 0.11 & \\
\hline $\mathrm{N}$ & 134 & & & & 134 & & & \\
\hline
\end{tabular}

MINI-Plus Mini International Neuropsychiatric Interview, ISCO International Standard Classification of Occupations, $I Q$ estimated intelligence quotient, MMSE Mini Mental State Examination, $A Q$ Autismspectrum Quotient, ADOS Autism Diagnostic Observation Schedule

$* p \leq .05 ; * * p \leq .01 ; * * * p \leq .001$ situations and, therefore, show less preoccupation and anxiety. Finally, it could be that older adults experience feelings of anxiety in social situations that are qualitatively different than aspects captured by this type of assessment, for example due to differential social settings and type of interactions (Ciliberti et al. 2011). Future research is needed to test which of these potential explanations will hold.

In line with previous studies in adults with ASD (García-Villamisar and Rojahn 2015; Sterling et al. 2008), individuals with more depression and anxiety symptoms also demonstrated more severe self-reported and observed ASD symptoms. When focusing on psychiatric disorders rather than symptoms, higher self-reported ASD symptomatology and lower age were associated with the presence of any lifetime anxiety disorder. This latest result confirmed the already observed trend in the age-group comparisons. Furthermore, female gender was associated with any lifetime mood disorder, indicating that females are more likely to receive a diagnosis of depression or dysthymia than males. Although in line with observations in the general population (Kessler et al. 2005), no such gender differences have been detected in previous adult ASD studies (Lai et al. 2011; Lugnegård et al. 2011). The use of self-report information (Lai et al. 2011) or the inclusion of young adults (Lugnegård et al. 2011) may account for this discrepancy. As aforementioned we did not find a relation between depressive symptoms and gender by means of self-report either and when we (post hoc) selected only young adults within our sample we also did not observe a gender difference on mood disorder. Hence, our findings do suggest that after young adulthood females with ASD are more vulnerable for mood disorder than males with ASD, just as reported in the general population. The other variables (i.e., intellectual and general cognitive functioning, social economic status [education and work], and living situation), selected for their consistent relationship with psychopathology in the general population, were notably not associated with depression and anxiety symptoms and disorders in the ASD group.

Our study suffers from a few limitations that are of importance to keep in mind when interpreting the findings. First, we did neither include an epidemiological sample nor did we adopt a longitudinal design. Therefore, our results can be an overestimation of prevalence rates (Howlin and Moss 2012) and cohort effects can bias our results. Within the current design the directionality of effect cannot be determined: For example, does more severe ASD symptoms cause more psychiatric problems, or is more severe ASD inherently related to psychopathology? Longitudinal research may shed light on this issue. Second, the structured nature of the MINI interview did not allow disentangling whether specific symptoms were characteristic of the investigated disorder or part of the ASD phenotype (e.g., OCD or social anxiety) (see Kerns and Kendall 2012; Wood and Gadow 2010). A promising approach that might shed light on the problem of defining diagnostic boundaries is presented by the network perspective in which mental disorders are conceptualized as networks of interacting symptoms rather than a latent construct (e.g., see Borsboom et al. 2011; Bringmann et al. 2013; Cramer et al. 2010). Third, although prevalence rates of psychiatric disorders in adults without ASD are largely comparable to those obtained in epidemiological studies including a general population sample (Bijl et al. 1998; Kessler et al. 2005), the frequency of substance-related disorders was high. This is mainly due to the prevalence of alcohol abuse (see Online Resource 1). 
Fourth, diagnostic information was obtained by means of self-report, even though we administered the ADOS to part of the ASD sample to substantiate ASD diagnoses. Yet, given the finding that group differences on a continuous measure of psychopathology were also present in this subsample, it is unlikely that our sampling method affected the main conclusions. Fifth, our findings apply to adults with ASD without ID and cannot be generalized to the entire ASD population. Finally, although we investigated many psychiatric disorders, we did not examine all. For example, schizophrenia, bipolar disorder, and personality disorders were not taken into consideration. Furthermore, we did not focus on medical comorbidities, even though we did collect information regarding the use of non-psychotropic medication. While the percentages of prescribed psychotropic drugs are in line with the high number of observed psychiatric diagnoses, the percentages of non-psychotropic medication use in the ASD and COM group were similar. This might suggest that there are no differences between groups with regard to medical conditions, but this would be a premature conclusion. Those with ASD might report less somatic complaints to their general practitioner due to reduced sensitivity to bodily signals or they might be more reluctant to access the healthcare system due to, for example, communication and social difficulties or anxiety for medical examination as a result of sensory sensitivities. Earlier studies focusing on medical conditions in ASD reported elevated rates compared to controls on many disorders, including epilepsy, gastrointestinal and sleep disorders, diabetes, and dyslipidemia (Croen et al. 2015; Kohane et al. 2012; Tyler et al. 2011). Hence, in future research it would be worthwhile not to merely focus on psychiatric comorbidities but also on somatic comorbidities.

To conclude, in this large ASD adult cohort study including older adults, we showed that psychopathology, and specifically social phobia, less frequently occurred in late adulthood. As these findings represent just an initial step into the understanding of psychopathology across the entire adult lifespan, further research into the nature of psychiatric co-occurring symptoms and disorders and intricate risk factors in old age is needed. Given that psychiatric problems are, however, still common and psychological distress is substantial, we need adequate interventions and support to reduce the personal burden of adults with ASD.

Acknowledgments We would like to thank all participants for their time and effort, research assistants Nynke Dicke and Barbara van Heijst for their overall help with conducting the study, and students for their help with data collection.

Author Contributions AGL participated in the design and the execution and coordination of the study, performed measurements and the statistical analysis and interpretation of the data, and wrote the manuscript; HMG supervised the study, participated in the design, the set-up of the statistical plan and interpretation of the data, and helped to draft the manuscript. Both authors read and approved the final manuscript.

Funding This study was funded by Innovational Research Incentives Scheme Vidi (NWO-MagW) awarded to Hilde M. Geurts (Grant Number 452-10-003).

\section{Compliance with Ethical Standards}

Conflict of interest The authors declare that they have no conflict of interest.

Ethical Approval All procedures performed in studies involving human participants were in accordance with the ethical standards of the institutional and/or national research committee and with the 1964 Helsinki declaration and its later amendments or comparable ethical standards.

Informed Consent Informed consent was obtained from all individual participants included in the study.

Open Access This article is distributed under the terms of the Creative Commons Attribution 4.0 International License (http://crea tivecommons.org/licenses/by/4.0/), which permits unrestricted use, distribution, and reproduction in any medium, provided you give appropriate credit to the original author(s) and the source, provide a link to the Creative Commons license, and indicate if changes were made.

\section{References}

Aman, M. G., Lam, K. S., \& Van Bourgondien, M. E. (2005). Medication patterns in patients with autism: Temporal, regional, and demographic influences. Journal of Child \& Adolescent Psychopharmacology, 15(1), 116-126.

American Psychiatric Association. (2000). Diagnostic and statistical manual of mental disorders (4th ed.). Washington, DC: Author.

American Psychiatric Association. (2013). The diagnostic and statistical manual of mental disorders (5th ed.). Washington, DC: Author.

Arrindell, W. A., \& Ettema, J. H. M. (2005). SCL-90 Handleiding bij een multidimensionale psychopathologie-indicator [SCL-90: Manual for a multidimensional indicator of psychopathology]. Amsterdam: Pearson.

Baron-Cohen, S., Wheelwright, S., Skinner, R., Martin, J., \& Clubley, E. (2001). The autism-spectrum quotient (AQ): Evidence from asperger syndrome/high-functioning autism, males and females, scientists and mathematicians. Journal of Autism and Developmental Disorders, 31(1), 5-17.

Bastiaansen, J. A., Meffert, H., Hein, S., Huizinga, P., Ketelaars, C., Pijnenborg, M., et al. (2011a). Diagnosing autism spectrum disorders in adults: The use of autism diagnostic observation schedule (ADOS) module 4. Journal of Autism and Developmental Disorders, 41(9), 1256-1266.

Bastiaansen, J. A., Thioux, M., Nanetti, L., van der Gaag, C., Ketelaars, C., Minderaa, R., \& Keysers, C. (2011b). Age-related increase in inferior frontal gyrus activity and social functioning in autism spectrum disorder. Biological Psychiatry, 69(9), 832-838.

Beekman, A. T., Bremmer, M. A., Deeg, D. J., Van Balkom, A., Smit, J. H., De Beurs, E., et al. (1998). Anxiety disorders in later life: 
A report from the longitudinal aging study amsterdam. International Journal of Geriatric Psychiatry, 13(10), 717-726.

Beekman, A. T., de Beurs, E., van Balkom, A. J., Deeg, D. J., van Dyck, R., \& van Tilburg, W. (2000). Anxiety and depression in later life: Co-occurrence and communality of risk factors. American Journal of Psychiatry, 157(1), 89-95.

Bellini, S. (2004). Social skill deficits and anxiety in high-functioning adolescents with autism spectrum disorders. Focus on Autism and Other Developmental Disabilities, 19(2), 78-86.

Bijl, R., Ravelli, A., \& Van Zessen, G. (1998). Prevalence of psychiatric disorder in the general population: Results of the Netherlands mental health survey and incidence study (NEMESIS). Social Psychiatry and Psychiatric Epidemiology, 33(12), 587-595.

Borsboom, D., Cramer, A. O., Schmittmann, V. D., Epskamp, S., \& Waldorp, L. J. (2011). The small world of psychopathology. PLoS One, 6(11), e27407.

Bringmann, L. F., Vissers, N., Wichers, M., Geschwind, N., Kuppens, P., Peeters, F., et al. (2013). A network approach to psychopathology: New insights into clinical longitudinal data. PLoS One, 8(4), e60188.

Buck, T. R., Viskochil, J., Farley, M., Coon, H., McMahon, W. M., Morgan, J., \& Bilder, D. A. (2014). Psychiatric comorbidity and medication use in adults with autism spectrum disorder. Journal of Autism and Developmental Disorders, 44(12), 3063-3071.

Cath, D. C., Ran, N., Smit, J. H., van Balkom, A. J., \& Comijs, H. C. (2008). Symptom overlap between autism spectrum disorder, generalized social anxiety disorder and obsessive-compulsive disorder in adults: A preliminary case-controlled study. Psychopathology, 41(2), 101-110.

Cederlund, M., Hagberg, B., \& Gillberg, C. (2010). Asperger syndrome in adolescent and young adult males. Interview, selfand parent assessment of social, emotional, and cognitive problems. Research in Developmental Disabilities, 31(2), 287-298.

Cervantes, P. E., \& Matson, J. L. (2015). Comorbid symptomology in adults with autism spectrum disorder and intellectual disability. Journal of Autism and Developmental Disorders, 45(12), 3961-3970.

Ciliberti, C., Gould, C., Smith, M., Chorney, D., \& Edelstein, B. (2011). A preliminary investigation of developmentally sensitive items for the assessment of social anxiety in late life. Journal of Anxiety Disorders, 25(5), 686-689.

Cramer, A. O., Waldorp, L. J., van der Maas, Han L. J., \& Borsboom, D. (2010). Comorbidity: A network perspective. Behavioral and Brain Sciences, 33(2-3), 137-150.

Croen, L. A., Zerbo, O., Qian, Y., Massolo, M. L., Rich, S., Sidney, S., \& Kripke, C. (2015). The health status of adults on the autism spectrum. Autism: The International Journal of Research and Practice, 19(7), 814-823.

Davis, T. E., Moree, B. N., Dempsey, T., Reuther, E. T., Fodstad, J. C., Hess, J. A., et al. (2011). The relationship between autism spectrum disorders and anxiety: The moderating effect of communication. Research in Autism Spectrum Disorders, 5(1), 324-329.

de Bildt, A., \& de Jonge, M. V. (2008). Autisme diagnostisch observatie schema. Amsterdam: Hogrefe.

de Bruin, E. I., Ferdinand, R. F., Meester, S., de Nijs, P. F., \& Verheij, F. (2007). High rates of psychiatric co-morbidity in PDD-NOS. Journal of Autism and Developmental Disorders, 37(5), 877-886.

Derogatis, L. R. (1977). Administration, scoring, and procedures manual for the SCL-90-R. Baltimore, MD: Clinical Psychometrics Research.

Esbensen, A. J., Seltzer, M. M., Lam, K. S., \& Bodfish, J. W. (2009). Age-related differences in restricted repetitive behaviors in autism spectrum disorders. Journal of Autism and Developmental Disorders, 39(1), 57-66.

Folstein, M. F., Folstein, S. E., \& McHugh, P. R. (1975). "Minimental state": A practical method for grading the cognitive state of patients for the clinician. Journal of Psychiatric Research, 12(3), 189-198.

García-Villamisar, D., \& Rojahn, J. (2015). Comorbid psychopathology and stress mediate the relationship between autistic traits and repetitive behaviours in adults with autism. Journal of Intellectual Disability Research, 59(2), 116-124.

Ghaziuddin, M., Ghaziuddin, N., \& Greden, J. (2002). Depression in persons with autism: Implications for research and clinical care. Journal of Autism and Developmental Disorders, 32(4), 299-306.

Ghaziuddin, M., \& Zafar, S. (2008). Psychiatric comorbidity of adults with autism spectrum disorders. Clinical Neuropsychiatry, 5(1), 9-12.

Gotham, K., Unruh, K., \& Lord, C. (2015). Depression and its measurement in verbal adolescents and adults with autism spectrum disorder. Autism, 19(4), 491-504.

Hofvander, B., Delorme, R., Chaste, P., Nydén, A., Wentz, E., Ståhlberg, O., et al. (2009). Psychiatric and psychosocial problems in adults with normal-intelligence autism spectrum disorders. BMC Psychiatry, 9(1), 35-44.

Holtmann, M., Bölte, S., \& Poustka, F. (2007). Autism spectrum disorders: Sex differences in autistic behaviour domains and coexisting psychopathology. Developmental Medicine and Child Neurology, 49(5), 361-366.

Howlin, P., \& Moss, P. (2012). In review-adults with autism spectrum disorders. Canadian Journal of Psychiatry, 57(5), 275-283.

IBM Corp. (2013). IBM SPSS statistics for windows (Version 22.0). Armonk, NY: IBM Corp.

Jang, J., \& Matson, J. L. (2015). Autism severity as a predictor of comorbid conditions. Journal of Developmental and Physical Disabilities, 27(3), 405-415.

Joshi, G., Wozniak, J., Petty, C., Martelon, M. K., Fried, R., Bolfek, A., et al. (2013). Psychiatric comorbidity and functioning in a clinically referred population of adults with autism spectrum disorders: A comparative study. Journal of Autism and Developmental Disorders, 43(6), 1314-1325.

Kerns, C. M., \& Kendall, P. C. (2012). The presentation and classification of anxiety in autism spectrum disorder. Clinical Psychology-Science and Practice, 19(4), 323-347.

Kessler, R. C., Berglund, P., Demler, O., Jin, R., Merikangas, K. R., \& Walters, E. E. (2005). Lifetime prevalence and age-of-onset distributions of DSM-IV disorders in the national comorbidity survey replication. Archives of General Psychiatry, 62(6), 593-602.

Kohane, I. S., McMurry, A., Weber, G., MacFadden, D., Rappaport, L., Kunkel, L., et al. (2012). The co-morbidity burden of children and young adults with autism spectrum disorders. PLoS One, 7(4), e33224.

Kooij, J. J. S., Buitelaar, J. K., van den Oord, E. J., Furer, J. W., Rijnders, C. A. T., \& Hodiamont, P. P. G. (2005). Internal and external validity of attention-deficit hyperactivity disorder in a population-based sample of adults. Psychological Medicine, 35(06), 817-827.

Kooij, J. J. S., Marije Boonstra, A., Swinkels, S. H., Bekker, E. M., de Noord, I., \& Buitelaar, J. K. (2008). Reliability, validity, and utility of instruments for self-report and informant report concerning symptoms of ADHD in adult patients. Journal of Attention Disorders, 11(4), 445-458.

Lai, M., Lombardo, M. V., Pasco, G., Ruigrok, A., Wheelwright, S. J., Sadek, S. A., et al. (2011). A behavioral comparison of male and female adults with high functioning autism spectrum conditions. PLoS One, 6(6), e20835. 
Lainhart, J. E. (1999). Psychiatric problems in individuals with autism, their parents and siblings. International Review of Psychiatry, 11(4), 278-298.

Lecrubier, Y., Sheehan, D., Weiller, E., Amorim, P., Bonora, I., Harnett Sheehan, K., et al. (1997). The mini international neuropsychiatric interview (MINI). A short diagnostic structured interview: Reliability and validity according to the CIDI. European Psychiatry, 12(5), 224-231.

Lever, A. G., \& Geurts, H. M. (2015a). Age-related differences in cognition across the adult lifespan in autism spectrum disorder. Autism Research. doi:10.1002/aur.1545.

Lever, A. G., \& Geurts, H. M. (2015b). Lifelong lasting? Self- and other-reported ASD symptoms across adulthood. Unpublished manuscript.

Leyfer, O. T., Folstein, S. E., Bacalman, S., Davis, N. O., Dinh, E., Morgan, J., et al. (2006). Comorbid psychiatric disorders in children with autism: Interview development and rates of disorders. Journal of Autism and Developmental Disorders, 36(7), 849-861.

Logan, S. L., Carpenter, L., Leslie, R. S., Garrett-Mayer, E., Hunt, K. J., Charles, J., \& Nicholas, J. S. (2015). Aberrant behaviors and co-occurring conditions as predictors of psychotropic polypharmacy among children with autism spectrum disorders. Journal of Child and Adolescent Psychopharmacology, 25(4), 323-336.

Lord, C., Risi, S., Lambrecht, L., Cook, E. H, Jr, Leventhal, B. L., DiLavore, P. C., et al. (2000). The autism diagnostic observation Schedule-Generic: A standard measure of social and communication deficits associated with the spectrum of autism. Journal of Autism and Developmental Disorders, 30(3), 205-223.

Lugnegård, T., Hallerbäck, M. U., \& Gillberg, C. (2011). Psychiatric comorbidity in young adults with a clinical diagnosis of asperger syndrome. Research in Developmental Disabilities, 32(5), 1910-1917.

Lundström, S., Reichenberg, A., Melke, J., Råstam, M., Kerekes, N., Lichtenstein, P., et al. (2015). Autism spectrum disorders and coexisting disorders in a nationwide swedish twin study. Journal of Child Psychology and Psychiatry, 56(6), 702-710.

Maddox, B. B., \& White, S. W. (2015). Comorbid social anxiety disorder in adults with autism spectrum disorder. Journal of Autism and Developmental Disorders, 45(12), 3949-3960.

Magiati, I., Tay, X. W., \& Howlin, P. (2014). Cognitive, language, social and behavioural outcomes in adults with autism spectrum disorders: A systematic review of longitudinal follow-up studies in adulthood. Clinical Psychology Review, 34(1), 73-86.

Matson, J. L., \& Cervantes, P. E. (2014). Commonly studied comorbid psychopathologies among persons with autism spectrum disorder. Research in Developmental Disabilities, 35(5), 952-962.

Mattila, M., Hurtig, T., Haapsamo, H., Jussila, K., Kuusikko-Gauffin, S., Kielinen, M., et al. (2010). Comorbid psychiatric disorders associated with asperger syndrome/high-functioning autism: A community-and clinic-based study. Journal of Autism and Developmental Disorders, 40(9), 1080-1093.

Moss, P., Howlin, P., Savage, S., Bolton, P., \& Rutter, M. (2015). Self and informant reports of mental health difficulties among adults with autism findings from a long-term follow-up study. Autism, 19(7), 832-841.

Mukaddes, N. M., Hergüner, S., \& Tanidir, C. (2010). Psychiatric disorders in individuals with high-functioning autism and asperger's disorder: Similarities and differences. The World Journal of Biological Psychiatry, 11(8), 964-971.

National Institute for Health and Clinical Excellence. (2012). Autism: Recognition, referral, diagnosis and management of adults on the autism spectrum. NICE clinical guideline 142. http:// guidance.nice.org.uk/CG142 (NICE guideline).
Perkins, E. A., \& Berkman, K. A. (2012). Into the unknown: Aging with autism spectrum disorders. American Journal on Intellectual and Developmental Disabilities, 117(6), 478-496.

Piven, J., Harper, J., Palmer, P., \& Arndt, S. (1996). Course of behavioral change in autism: A retrospective study of high-IQ adolescents and adults. Journal of the American Academy of Child and Adolescent Psychiatry, 35(4), 523-529.

Pugliese, C. E., Kenworthy, L., Bal, V. H., Wallace, G. L., Yerys, B. E., Maddox, B. B., et al. (2015). Replication and comparison of the newly proposed ADOS-2, module 4 algorithm in ASD without ID: A multi-site study. Journal of Autism and Developmental Disorders, 45(12), 3919-3931.

Ring, M., Gaigg, S. B., \& Bowler, D. M. (2015). Relational memory processes in adults with autism spectrum disorder. Autism Research. doi:10.1002/aur.1493.

Roy, M., Prox-Vagedes, V., Ohlmeier, M. D., \& Dillo, W. (2015). Beyond childhood: Psychiatric comorbidities and social background of adults with asperger syndrome. Psychiatria Danubina, 27(1), 50-59.

Sartorius, N., Üstün, T. B., Lecrubier, Y., \& Wittchen, H. (1996). Depression comorbid with anxiety: Results from the WHO study on "psychological disorders in primary health care". The British Journal of Psychiatry, 168(30), 38-43.

Seltzer, M. M., Shattuck, P., Abbeduto, L., \& Greenberg, J. S. (2004). Trajectory of development in adolescents and adults with autism. Mental Retardation and Developmental Disabilities Research Reviews, 10(4), 234-247.

Sheehan, D., Lecrubier, Y., Harnett Sheehan, K., Janavs, J., Weiller, E., Keskiner, A., et al. (1997). The validity of the mini international neuropsychiatric interview (MINI) according to the SCID-P and its reliability. European Psychiatry, 12(5), 232-241.

Sheehan, D., Lecrubier, Y., Sheehan, K., Amorim, P., Janavs, J., Weiller, E., et al. (1998). The mini-international neuropsychiatric interview (M.I.N.I.): The development and validation of a structured diagnostic psychiatric interview for DSM-IV and ICD-10. Journal of Clinical Psychiatry, 59, 22-33.

Simonoff, E., Jones, C. R., Baird, G., Pickles, A., Happé, F. G. E., \& Charman, T. (2013). The persistence and stability of psychiatric problems in adolescents with autism spectrum disorders. Journal of Child Psychology and Psychiatry, 54(2), 186-194.

Simonoff, E., Pickles, A., Charman, T., Chandler, S., Loucas, T., \& Baird, G. (2008). Psychiatric disorders in children with autism spectrum disorders: Prevalence, comorbidity, and associated factors in a population-derived sample. Journal of the American Academy of Child and Adolescent Psychiatry, 47(8), 921-929.

Sinzig, J., Walter, D., \& Doepfner, M. (2009). Attention deficit/ hyperactivity disorder in children and adolescents with autism spectrum disorder symptom or syndrome? Journal of Attention Disorders, 13(2), 117-126. doi:10.1177/1087054708326261.

Sterling, L., Dawson, G., Estes, A., \& Greenson, J. (2008). Characteristics associated with presence of depressive symptoms in adults with autism spectrum disorder. Journal of Autism and Developmental Disorders, 38(6), 1011-1018.

Stevens, J. P. (2012). Applied multivariate statistics for the social sciences. New York, NY: Routledge.

Totsika, V., Felce, D., Kerr, M., \& Hastings, R. P. (2010). Behavior problems, psychiatric symptoms, and quality of life for older adults with intellectual disability with and without autism. Journal of Autism and Developmental Disorders, 40(10), 1171-1178.

Trimbos. (2013). Multidisciplinaire richtlijn diagnostiek en behandeling van autismespectrumstoornissen bij volwassenen. Utrecht: De Tijdstroom.

Tureck, K., Matson, J. L., Cervantes, P., \& Konst, M. J. (2014). An examination of the relationship between autism spectrum 
disorder, intellectual functioning, and comorbid symptoms in children. Research in Developmental Disabilities, 35(7), 1766-1772.

Tyler, C. V., Schramm, S. C., Karafa, M., Tang, A. S., \& Jain, A. K. (2011). Chronic disease risks in young adults with autism spectrum disorder: Forewarned is forearmed. American Journal on Intellectual and Developmental Disabilities, 116(5), 371-380.

Uterwijk, J. (2000). WAIS-III nederlandstalige bewerking. Technische handleiding. Lisse: Swets \& Zeitlinger.

van Heijst, B. F. C., \& Geurts, H. M. (2014). Quality of life in autism across the lifespan: A meta-analysis. Autism, 19(2), 158-167.

van Steensel, F. J., Bögels, S. M., \& de Bruin, E. I. (2013). Psychiatric comorbidity in children with autism spectrum disorders: A comparison with children with ADHD. Journal of Child and Family Studies, 22(3), 368-376.

van Steensel, F. J., Bögels, S. M., \& Dirksen, C. D. (2012). Anxiety and quality of life: Clinically anxious children with and without autism spectrum disorders compared. Journal of Clinical Child \& Adolescent Psychology, 41(6), 731-738.

van Vliet, I. M., Leroy, H., \& van Megen, H. J. G. M. (2000). De MINI internationaal neuropsychiatrisch interview, nederlandse versie 5.0.0. Leiden: Leiden University Medical Center, Department of Psychiatry.
Vannucchi, G., Masi, G., Toni, C., Dell’Osso, L., Marazziti, D., \& Perugi, G. (2014). Clinical features, developmental course, and psychiatric comorbidity of adult autism spectrum disorders. CNS Spectrums, 19(02), 157-164.

Verheij, C., Louwerse, A., van der Ende, J., Eussen, M., Van Gool, A., Verheij, F., et al. (2015). The stability of comorbid psychiatric disorders: A 7 year follow up of children with pervasive developmental disorder-not otherwise specified. Journal of Autism and Developmental Disorders, 45(12), 3939-3948.

Wechsler, D. (1997). Wechsler adult intelligence scale (WAIS-III). San Antonio, TX: Psychological Corporation.

Wolitzky-Taylor, K. B., Castriotta, N., Lenze, E. J., Stanley, M. A., \& Craske, M. G. (2010). Anxiety disorders in older adults: A comprehensive review. Depression and Anxiety, 27(2), 190-211.

Wood, J. J., \& Gadow, K. D. (2010). Exploring the nature and function of anxiety in youth with autism spectrum disorders. Clinical Psychology: Science and Practice, 17(4), 281-292.

Woodbury-Smith, M., Robinson, J., Wheelwright, S., \& BaronCohen, S. (2005). Screening adults for asperger syndrome using the AQ: A preliminary study of its diagnostic validity in clinical practice. Journal of Autism and Developmental Disorders, 35(3), $331-335$. 